\title{
Consideraçōes sobre a produção de alimentos por árvores e florestas (1)
}

\author{
D. B. Arkcoll ${ }^{(2)}$
}

\begin{abstract}
Resumo
Arvores e florestas contribuom com pouco alimento para a maioria das dietas humanas. No entanto, algumas espécies, aparentemente, são capazes de produzir mais alimentos por área do que muitas das culturas anuais que nos fornecem a maioria de nossos alimentos. Este trabalho sugere que esse potencial de alto rendimento dos alimentos de origem florestal, junto com outras vantagens agrícolas e ecológicas, devem estimular pesquisas sobre o aumento na produção de alimentos de todos os tipos de florestas e o planejamento de "florestas de alimentos".
\end{abstract}

\section{ALIMENTOS DE FLoRestas NAtURAis}

Embora algumas florestas naturais sejam ricas em árvores que produzem grande quantidade de alimentos, por exemplo, os $12 \mathrm{mi}-$ Ihões de hectares de floresta de babaçu no Brasil, a maioria produz somente pequenas quantidades. Assim, tanto, os animais da floresta como as populações humanas que dependem de caça e de collheita da mata estão dispersos. Tais populações são também freqüentemente nômades, pois os animais são rapidamente caçados, próximo aos povoados (Gross, 1975). Esta escassez de alimento e a disponibilidade irregular, através dos anos, foram fatores importantes na mudança de nossos ancestrais em agricultores e pastores.

Contudo, a floresta e, especialmente, a floresta tropical, oculta uma vasta quantidade de frutas, castanhas, raízes, caules, seivas, foIhas, animais, abelhas fungos e caracóis (lesmas) que podem ter potencial como alimentos domésticos. A perda de tais espécies e sua diversidade genética são, provavelmente, as mais sérias conseqüências do desmatamento da floresta natural. Muito mais esforço deveria ser gasto na coleta e avaliação destes recursos que estão sendo perdidos tão exageradamente (Clement \& Arkcoll, 1979; Grainger, 1980).

Parece conveniente considerar, também, alguns dos alimentos que poderiam ser ministrados racionalmente dentro da floresta natural. Algumas plantas tolerantes à sombra, certos animais da floresta e alimentos de luxo, como caracóis, fungos e mel poderiam talvez ser cultivados por pequenos produtores para suplementar suas dietas e rendas. Freqüentemente, esquece-se que a criação de suínos em florestas era uma prática muito comum na maior parte da Europa até pouco tempo atrás. De fato, era tão importante na Inglaterra que os bosques eram medidos pelo número de porcos que poderiam produzir, em vez de por sua área, A prática é ainda comum nas florestas de carvalho do sul de Portugal, na Nova Guiné e nes plantações de bananas equadorianas. Outros animais de floresta, selvagens ou domesticados, poderiam ser mais adequados; estamos obtendo resultados bem encorajadores com galinhas, que são bem adaptadas a consumir o abundante número de insetos das florestas tropicais.

\section{Alimentos DE PLANTAÇões Florestais}

Tais sistemas de produção poderiam também ser usados em plantações florestais que deviam ser melhorados pela seleção de espécies florestais que produzam mais alimento. Por exemplo, espécies que produzem forragem, fruto e semente aumentariam o número de animais que poderiam ser estocados.

Talvez o principal problema da silvicultura, hoje, seja que é proveitoso derrubar florestas sem todavia replantá-las, porque a agricul-

\footnotetext{
(1) - Versão portuguesa do trabalho apresentado no "International Symposium on Forest Sciences and their contribution to the davelopment of Tropical America". CONICIT-INTERCIENCIA-SCITEC SÃO JOSE - Costa Rica. 1979. Proceedings Publ. by EUNED, SAO JOSÉ. 1981.

(2) - Instituto Nacional de Pesquisas da Amazônia, Manaus.
} 
tura fornece lucros maiores e imediatos. Conseqüentemente, plantações de espécies florestais são efetuadas nas tcrras consideradas desfavoráveis para agricultura c freqüentemente exigem subsídios ou implementos governamentais. Logo, a rentabilidade da silvicultura deve ser aperfeiçoada, para que possa competir com a agricultura. Sistemas agrossilvícolas constituem excelente maneira de fornecer tanto alimento quanto renda, especialmente nos anos iniciais. Outra fonte de renda que estamos sugerindo para nossos engenheiros florestais é usar madeiras de lei que também produzam um fruto valioso como a castanha-do-pará (Bertholletia excelsa), Dipteryx odorata, a andiroba (Carapa guianensis) etc.

\section{PLANTAÇões DE CASTANHeiras E FRUTífERAS}

Embora comamos os frutos e as castanhas de muitas espécies de árvores, estas compõem uma pequena parte da maioria de nossas dietas. Isto é porque a maioria dos frutos é pobre em nutrientes o nosso consumo de castanhas nutritivas é pequeno porque elas são caras e pouco disponiveis. É surpreendente que isto ocorre porque as culturas perenes são, em gera!, as mais rentáveis das opções agrícolas. Infelizmente, apenas pequenas áreas da maioria de frutíferas e castanheiras são cultivadas, isto porque elas são negligenciadas nos cursos de agronomia e silvicultura e a maioria dessas frutciras leva vários anos antes de começar a produzir. Este fator "tempo" também acimenta o desinteresse geral dos pesquisadores.

Existem, é claro, algumas espécies que são importantes para alguns de nós, como bananas e óleo de palmeiras. Este último item fornece cerca de $20 \%$ da produção de óleo do mundo, e ajuda a atingir os $40 \%$ de exigência calórica que, em muitos países descnvolvidos, provém do óleo e gordura. O óleo de dendê está tornando-se cada vez mais importante, à medida que as modernas plantações chegam a produzir safras do mais de $5 \mathrm{t}$ de óleo por hectare. Isto é cerca de dez vezes a produção dé óleo de soja. Um aumento da produção considerável é esperado agora que as melhores árvores podem ser exploradas usando-se a técnica de cultura de tecidos.

Muitos povos pobres, em países em desenvolvimento também obtêm grande quantidade de calorias não registradas pelo grande consumo de frutos de árvores comuns nos quintais como bananas, mangas, jaca, frutapão, abacate, pupunha etc. Algumas destas formam, mesmo a principal fonte de amido da dieta de populaçōes em. pequenas áreas do mundo. São exemplos a fruta-pão no Pacífico Sul e Antilhas, banana pacovão (= plântano) em Uganda e Equador e as pupunhas em algumas partes da Amazônia e América Central.

\section{FLORESTAS DE ALIMENTOS}

Apesar da falta de dados de pesquisa, as produções de muitas destas frutas amiláceas parecem ser duas ou mais vezes maiores por área do que as de nossos cereais comuns. É tentador perguntar quanto estas produções poderiam ser aumentadas por técnicas modernas de melhoramento genético e manejo. Estes rendimentos resultam de uma combinação da alta eficiência fotossintética devida a sua grande área foliar de longa duração, e uma excelente captação de nutrientes por uma estrutura extensiva e permanente da raiz (Newbould, 1971). Outras vantagens agrícolas incluem a liberdacde do trabalho, tempo e custo do plantio e cultivo anuais, uma alta resistência a doenças, secas e inundações, o uso de terras inclinadas e pedregosas e a produção simultânea de trepadeiras úteis, plantas de cobertura e animais. A simples reciclagem de cinzas e dejetos humanos com frutíferas também é possível quando crescem ao lado de fogos, esgotos, sepulturas, privadas etc. Estamos obtendo boris resultados, movendo "privadas produtivas", mensalmente, para adubar os pomares de pequenos lavradores, sem nenhum custo (Arkcoll, 1978). Isto é um considerável avanço sobre a perda e concentração de nutrientes usualmente encontradas em pequenas lavouras e sobre o desagradável trabalho e problemas higiênicos associados com a maioria dos métodos atuais de uso de excre- 
mentos em culturas anuais (Arkcoll, 1979a). Florestas de árvores frutiferas ofereceriam também todas as outras vantagens ecológicas de qualquer floresta, tais como controle de erosão e inundações, manutenção do clima etc. (Arkcoll, 1979b).

Como resultante destas numerosas vantagens, começamos a estudar mais seriamente o conceito completo de produzir nosso alimento de árvores. As sementes de espécies adequadas estão sendo coletadas e selecionadas e experimentos de campo estão em progresso para testar o espaçamento, necessidades de adubo e associações de culturas apropriadas.

A principal desvantagem é a mudança de hábitos alimentares. Como os principais frutos que formam a base do sistema são de pouco sabor, sente-se que uma combinação de práticas de cozimento, tecnologia moderna de alimento e propaganda seriam capazes de resolver o problema. C.ertamente parece valer a pena tentar.

\section{Summary}

Trees and forest contribute little to most diets. This is surprising as some species seem capable of producing much more food per area than the many annual crops that supply the bulk of our food. It is suggested that this yield potential coupled with agri- cultural e ecological advantages should lead to research into increasing food production from all forms of forests and the design of "food forests".

\section{REFERENCIAS BIBLIOGRAFICAS}

ARKCOLL, D.B.

1978 - Food Forests - an Alternative to Shifting cultivation. Abstr. of the XI International Nutrition Congress. Rio de Janeiro, 471.

$1979 a$ - Nutrient recycling as an Alternative to Shifting Cultivation. In: The Proceedings of a Conference on Ecodevelopment and Ecofarming. Berlin Science Foundation. Pergamon Press. No prelo. 1982.

1979b- Uma avaliação das opçōes Agro-silviculturais para Amazônia, em Anais do Simpósio sobre Ciências Básicas e Aplicadas. Academia de Ciências do Estado de São Paulo. Publicaçăo n. 19: 101-111.

CLEMENT, C.R. \& ARKCOLL, D.B.

1979 - A Política florestal e o futuro promissor da fruticultura na Amazônia. In: Acta Amazonica, 9 (4) sup. 173-177.

GRAINGER, A.

1980 - The State of the Worlds Tropical Forests. In: The Ecologist, 10: 6-54.

GROSS, D.L.

1975 - Protein Capture and Cultural Development in the Amazon Valley. In: American Anthropologist, 77 : $526-549$.

NEWBOULD, P.J.

1971 - Comparative Production of Ecosystems, London. In: Potential Crop Production, Waring, P.F. \& Cooper, J.P. ed. Heinemann Ed. Books, p. 228-238.

(Aceito para publicação em 16/05/80) 